\title{
Ocular myositis as first presenting symptom of human immunodeficiency virus (HIV-1) infection and its response to high-dose cortisone treatment
}

\author{
Eva-Maria Fabricius, Ingo Hoegl, Wolfgang Pfaeffl
}

\begin{abstract}
A 30-year-old male presented with signs of ocular inflammation and motility disturbances in an early stage of HIV infection. The provisional diagnosis of an ocular myositis was confirmed by orbital echograms. A general check up revealed positive anti-smoothmuscle antibodies and antinuclear antibodies as well as a raised erythrocyte sedimentation rate. Oral steroid treatment in addition to steroid eyedrops achieved complete resolution of clinical and sonographic symptoms within 15 weeks. Autoimmune phenomena are well known presentations of HIV infection. In this case oral cortisone proved to be an effective therapy even in the setting of an HIV infection.
\end{abstract}

Various forms of myositis are known in the course of an HIV infection - for example, as a possibly rheumatic manifestation,' as a complication of virustatic therapy with zidovudine, ${ }^{2}$ or as pyomyositis due to a secondary infection with bacteria $^{3}$ or protozoa. ${ }^{+}$Moreover, some cases of polymyositis in the early stages of HIV infection have been described in which HIV-1 itself was found in CD4-positive inflammatory cells surrounding or invading damaged muscle fibres. ${ }^{5}$ Here we report on a patient with ocular myositis as the presenting symptom of an HIV-1 infection and its therapeutic response to highdose cortisone therapy.

\section{Case report}

The patient, a 30-year-old male, had already complained for a few weeks of lassitude, headache, eye related pain, swelling of the eyelids and conjunctiva, reddening of the eyes, and double vision, until he consulted us in March 1989. Treatment with antibiotic-steroid eyedrops administered up to that time had not resulted in any improvement.

On examination the visual acuity was $20 / 20$ in

Munich, Germany,

Department of

Ophthalmology,

Harlaching Hospital

E M Fabricius

W Pfaeff

IV. Department of Medicine, Schwabing

Hospital

I Hoegl

Correspondence to:

Dr med Eva-Maria Fabricius,

Department of

Ophthalmology, Harlaching

Hospital, Sanatoriumsplatz 2,

D-8000 München 90 ,

Germany.

Accepted for publication

12 April 1991 both eyes. Both upper and lower lids were swollen. Apart from a tarsal conjunctivitis a slight bulbar conjunctivitis, an episcleritis, and slight conjunctival oedema were noted. The deeper eye segments were normal. In primary position the eyes were parallel. Motility testing revealed restriction of elevation and abduction of the right eye and restriction of abduction of the left eye. In the corresponding gaze directions the patient had double vision. The provisional diagnosis of an ocular myositis was confirmed by an ultrasonogram of the orbit. The patient was admitted to hospital for a general check up by electrocardiogram, chest $x$ ray, cerebral com- puted tomogram, and a physical examination. All results were negative. Lymphadenopathy and oral candidiasis were absent. An abdominal sonogram showed no splenomegaly or enlarged abdominal lymph nodes.

Laboratory tests revealed a raised erythrocyte sedimentation rate (Westergren) of $27 \mathrm{~mm}$ after one hour. The differential blood count, platelets, and serum enzymes, in particular creatinine kinase, were within the normal range. Electrophoresis showed a slightly raised gammaglobulin fraction. The level of IgE was within the normal range. Tests for anti-smooth-muscle antibodies (ASMA) and antinuclear antibodies (ANA) gave positive results, whereas other autoantibodies could not be detected. A reduced CD4/CD8 ratio of 0.62 , with an absolute CD4-positive cell count of $526 \times 10^{6} / 1$ resulted in testing for HIV infection. An enzyme linked immunosorbent assay (ELISA) test for HIV-1 antibodies showed positive results and was confirmed by Western blot. IgG antibodies in low titres were also demonstrated for Epstein-Barr virus, cytomegalovirus, herpes simplex virus, and toxoplasmosis. The Treponema pallidum haemagglutinin test was negative. Other infections in stool, sputum, and blood samples were excluded.

In addition to steroid eyedrops, oral steroid treatment was started with a daily dose of $1.5 \mathrm{mg} / \mathrm{kg}$ body weight fluocortolone for five days. The initial daily dose was tapered to $0.3 \mathrm{mg} / \mathrm{kg} /$ day over the next 20 days. The clinical symptoms resolved only slowly while changing their pattern (the left superior rectus muscle became temporarily paretic, and the episcleritis affected different locations of the bulbus before it resolved), so that the patient was maintained on this daily dose for another six weeks. After a further five weeks on a daily dose of $0.12 \mathrm{mg} / \mathrm{kg}$ body weight fluocortolone the systemic treatment was stopped, when complete resolution of the clinical symptoms was achieved and the sonographic controls of the eye muscles were normal (Fig 1).

Since then, after a follow-up of 15 months, the

\section{Discussion}

The pathogenesis of HIV associated myositis is not entirely clear. Apart from an invasion of the musculature by HIV infected inflammatory cells ${ }^{5}$ our case of ocular myositis perhaps sug- 
Figure 1 Standardised Ascan echograms of the orbit in ocular myositis

(G Hasenfratz, Department of Ophthalmology, LudwigMaximilians-University of Munich). Top (5 April 1989): Acute myositis: broadening (short arrows) of the muscle insertion region and massive broadening in the region of the belly of the muscle with appreciably lowered reflectivity of the muscle tissue and a

homogeneou internal structure (long arrow). Bottom (6 fune 1989): Decline of the muscle broadening (short arrows) and rise of the muscle reflectivity (long arrow) after systemic steroid therapy.
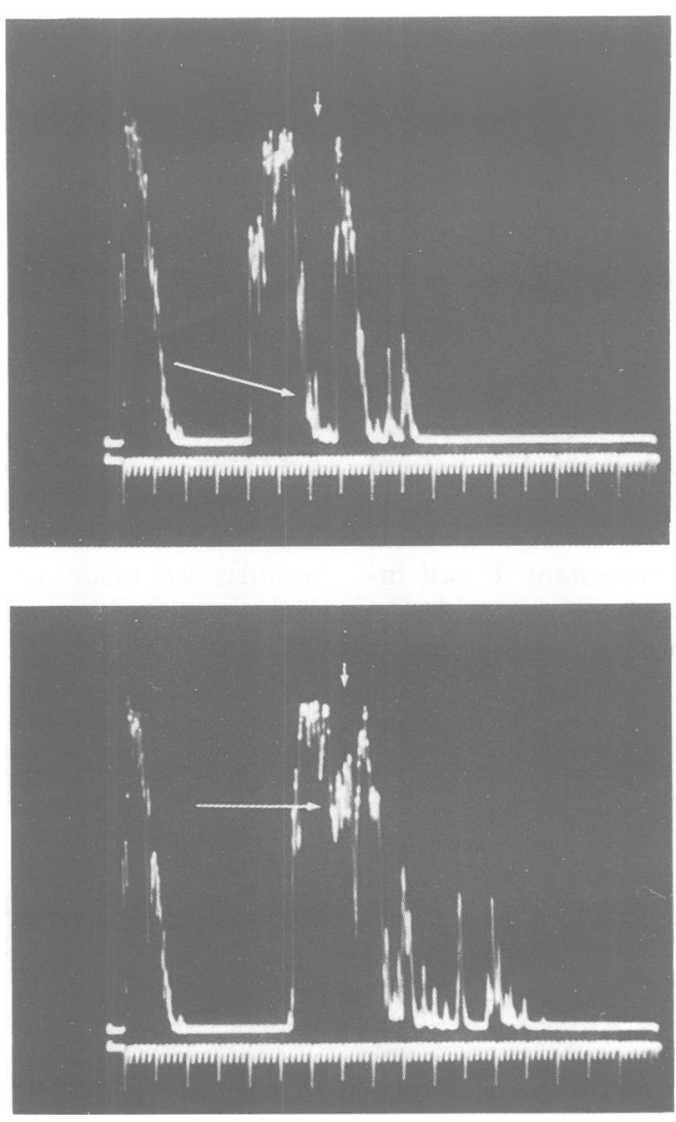

gests an autoimmune mechanism. Autoimmune phenomena are well known presentations of the HIV infection. In HIV infection autoantibodies against lymphocytes, ${ }^{6}$ platelets, ${ }^{7}$ nerve tissue, ${ }^{8}$ and other cell structures have been demonstrated. They are signs of the complex loss of a normal immune regulation in these patients. Poly- myositis as the initial manifestation of HIV infection has been recognised, ${ }^{59}$ but to the best of our knowledge this is the first report of an ocular myositis as the first presenting symptom of HIV infection. The presence of autoantibodies and good therapeutic response to cortisone in our case supports an autoimmune mechanism. Normal muscle enzymes in HIV associated myositis have been observed. ${ }^{10}$ In our patient high dose oral cortisone proved to be an effective therapy even in the setting of an HIV infection.

This work was supported by a grant from the Bundesminister für Forschung und Technologie, FKZ III-002-89.

1 Berman A, Espinoza LR, Diaz JD, Aguilar JL, Rolando T, Vasey FB, et al. Rheumatic manifestations of human immunodeficiency virus infection. Am $\mathcal{F}$ Med 1988; 85: 59-64.

2 Fischl $M$, Gagnon S, Uttamachandani R, Patrone-Reese J, Dearmas L, Tarras S, et al. Myopathy associated with long Dearmas L, Tarras S, et al. Myopathy associated with long term zidovudine therapy. Abstract no MBP329.

3 Watts RA, Hoffbrand BI, Paton DF, Davis JC. Pyomyositis associated with human immunodeficiency virus infection. BrMed F 1987; 294: 1524.

4 Macher AM, Neafie R, Angritt P, Tuur SM. Microsporidial myositis and the acquired immunodeficiency syndrome (AIDS): a four-year follow up. Ann Intern Med 1988; 109: 343.

5 Dalakas MC, Pezeshkpour GH, Gravell M, Sever JL. Polymyositis associated with AIDS retrovirus. FAMA 1986; 256 : 2381-3.

6 Kiprov DD, Anderson RE, Morand PR, Simpson D, Cherman J-C, Levy JA, et al. Antilymphocyte antibodies and seropositivity for retroviruses in groups at high risk for and seropositivity for retroviruses in

7 Stricker RB, Abrams DI, Corash I, Shuman MA. Target platelet antigen in homosexual men with immune thrombocytopenia. N Engl F Med 1985; 313: 1375-80.

8 Miller RG, Parry GJ, Pfaeff W, Lang W, Lippert R, Kiprov $D$. The spectrum of peripheral neuropathy associated with ARC and AIDS. Muscle Nerve 1988; 11: 857-63.

9 Altenkirch H, Stolitenburg-Didinger G, Rolfs A, Marx P. Myositis als Erstmanifestation ei einem HIV-1-positiven Patienten aus einer 'Nichtrisikogruppe' Med Klin 1988; 83: 192-4.

10 Scott JA, Palmer EL, Fischman AJ. HIV-associated myositis detected by radionuclide bone scanning. $\mathcal{F}$ Nucl Med 1989; 30: $556-8$. 